\title{
Article \\ Evaluation of Germplasm and Development of Markers for Resistance to Plasmodiophora brassicae in Radish (Raphanus sativus L.)
}

\author{
Qingbiao Wang ${ }^{1,2,3,+}$, Yanping Wang ${ }^{1,2,3,+}$, Huihui Qian ${ }^{1,2,3}$, Ziye Zhang ${ }^{1,2,3}$ and Li Zhang $1,2,3, *$ \\ 1 National Engineering Research Center for Vegetables, Beijing Academy of Agriculture and Forestry Sciences, \\ Beijing 100097, China; wangqingbiao@nercv.org (Q.W.); wangyanping@nercv.org (Y.W.); \\ qianhuihui2022@163.com (H.Q.); zhangziye2022@163.com (Z.Z.) \\ 2 Key Laboratory of Biology and Genetic Improvement of Horticultural Crops (North China), Ministry of \\ Agriculture and Rural Affairs of the People's Republic of China, Beijing 100097, China \\ 3 Beijing Key Laboratory of Vegetable Germplasm Improvement, Beijing 100097, China \\ * Correspondence: zhangli@nercv.org; Tel.: +86-10-51503163 \\ + These authors contributed equally to this work.
}

check for updates

Citation: Wang, Q.; Wang, Y.; Qian, H.; Zhang, Z.; Zhang, L. Evaluation of Germplasm and Development of Markers for Resistance to Plasmodiophora brassicae in Radish (Raphanus sativus L.). Agronomy 2022, 12, 554. https://doi.org/10.3390/ agronomy12030554

Academic Editors: Gianni Barcaccia, Alessandro Vannozzi and Fabio Palumbo

Received: 2 January 2022

Accepted: 16 February 2022

Published: 23 February 2022

Publisher's Note: MDPI stays neutral with regard to jurisdictional claims in published maps and institutional affiliations.

Copyright: (C) 2022 by the authors. Licensee MDPI, Basel, Switzerland. This article is an open access article distributed under the terms and conditions of the Creative Commons Attribution (CC BY) license (https:// creativecommons.org/licenses/by/ $4.0 /)$.

\begin{abstract}
The rapid spread of clubroot disease caused by Plasmodiophora brassicae threatens radish (Raphanus sativus) production in China because some cultivation types lack clubroot-resistant (CR) genes. However, few molecular markers for clubroot resistance have been developed and used in hybrid breeding programs. In this study, 27 immune and 6 highly resistant accessions were identified among 95 radish inbred lines. The genes Rsa10003637 and Rsa10025569/Rsa10025571 were respectively identified from an XYB36-2 reference genome as the homologs of Crr1 and CRa from Brassica rapa by means of homology and synteny analysis. The association between the degree of clubroot resistance and the genotype of these CR genes suggested that Rsa10025569-H3 can be used as a clubroot-resistant haplotype. The sequence identity of Rsa10025569 in clubroot-resistant lines (CR-60 and CR-88) and clubroot-susceptible lines (CR-10 and CR-35) was 92.47\%, and there was a $699 \mathrm{bp}$ insertion at the end of the fourth exon in the clubroot-susceptible line. Association analysis of a $\mathrm{BC}_{1} \mathrm{~F}_{1}$ population derived from the cross $\mathrm{CR}-88$ (resistance) $\times \mathrm{CR}-10$ (susceptible) revealed an apparent correlation between polymorphisms at the Rsa10025569 locus and degree of clubroot resistance. On the basis of the results, molecular marker-assisted selection was used to transfer disease resistance genes to susceptible varieties and a new CR germplasm of Xinlimei was obtained.
\end{abstract}

Keywords: radish germplasm; clubroot resistance; Plasmodiophora brassicae; CRa; marker-assisted selection

\section{Introduction}

Clubroot disease caused by Plasmodiophora brassicae is a serious threat to cruciferous crop production worldwide [1]. After infection of a susceptible host, root growth is depressed, and the roots form large distorted swellings or clubs, and the quality and commercial value of the crop products are reduced. Severely infected host plants exhibit wilting or die as a result of reduced absorption of water and nutrients [2,3]. P. brassicae has a complex life cycle consisting of three distinct stages: resting spores in the soil, primary infection of root hairs, and secondary infection within root cortical cells [4]. Eventually, the pathogen forms numerous resting spores in the infected tissues, which are released into the soil when the tissues disintegrate. The spores remain viable in the soil for long periods and the disease is difficult to control by means of cultural practices or fungicide application [5].

In China, clubroot disease was reported frequently in the 1950s and gradually spread throughout the country [6]. Approximately 3.2-4.0 million ha of cruciferous crops are infected annually, resulting in $20-30 \%$ yield loss $[7,8]$. Seven physiological races of $P$. brassicae have been detected in the main cruciferous planting areas of China based on the Williams' 
differential system, of which pathotype 4 is widely distributed in the country [8-10]. More recently, Pang et al. detected 16 pathotypes, designated $\mathrm{Pb} 1$ to $\mathrm{Pb} 16$, from 132 field isolates using a Sinitic clubroot differential (SCD) set. Pathotype 4 of Williams' set showed immense diversity and was differentiated into 11 pathotypes $(\mathrm{Pb} 1-\mathrm{Pb} 11)$ according to the SCD set. Among these pathotypes, $\mathrm{Pb} 1$ and $\mathrm{Pb} 4$ were prevalent in various cruciferous crops in the southern and northern regions of China [11].

Breeding clubroot-resistant (CR) varieties is the most effective strategy for prevention and control of this disease. Before initiating a breeding program, it is important to evaluate the resistance of germplasm. Subsequently, development of suitable molecular markers for a CR gene, which improve the accuracy and efficiency of backcrossing, is required. Multiple $C R$ genes have been identified or cloned in Brassica crops, such as $C R a$ [12,13], $C R b$ [14], Crr1, Crr2, and Crr4 [15-17], Crr3 [18,19], CRc and CRk [20], PbBa3.1 and PbBa3.3 [21], QS_B3.1 [22], CRd [23], and PbBrA08 [24]. Most of these genes are race-specific and derived from European fodder turnip (Brassica rapa subsp. rapa) [23]. Resistance to P. brassicae has been introduced from turnip into Chinese cabbage (B. rapa subsp. pekinensis), oilseed rape (B. napus), and cabbage (B. oleracea) to successfully generate new clubroot-resistant cultivars $[25,26]$. Among these resistance genes, $C R a$ and $\mathrm{Cr} r 1 a$ have been cloned and encode Toll/interleukin-1 receptor-like domain-nucleotide binding site-leucine-rich repeat (TIR-NBS-LRR) proteins, and $C R b$ is identical to $C R a$ [14]. Two gene/quantitative trait locus (QTL) clustering regions on chromosome A03, $C R a / C R b / Q S \_B 3.1$ (about $25 \mathrm{M}$ ) and $\mathrm{Crr} 3 / \mathrm{CRk} / \mathrm{PbBa3} .3$ (about $16 \mathrm{M}$ ), are loci with potential for further utilization in breeding [23]. Genome-wide analysis of single-nucleotide polymorphisms revealed the top and bottom segments of chromosome A03 and the middle segment of chromosome A08 of rutabaga (B. napus var. napobrassica) to be genomic hotspots associated with resistance to $P$. brassicae pathotypes [27].

With regard to radish, there are few reports of clubroot-resistance evaluation, QTL identification, and molecular marker development, and little information is available on the molecular mechanisms of resistance to clubroot. Sixty-eight radish cultivars and breeding lines were previously evaluated for clubroot resistance and most of the American radishes tested were moderately to highly susceptible; all of the Japanese and many of the Dutch cultivars were completely resistant [28]. Yang et al. identified 13 immune, 5 highly resistant, and 21 resistant accessions from among 349 radish accessions [29]. A major clubrootresistance QTL ( $\mathrm{Cr}$ 1) has been identified, and synteny analysis suggests that this region in radish and the $\mathrm{Crr} 3$ region in $\mathrm{B}$. rapa originate from the same ancestral genomic region [30]. Gan et al. identified five QTLs ( $\mathrm{RsCrl}, \mathrm{RsCr}_{2}, \mathrm{RsCr} 3, \mathrm{RsCr} 4$, and $\left.\mathrm{RsCr} 5\right)$ associated with radish clubroot resistance, among which $\mathrm{Rs} C r 4$ showed synteny with the $C r r 1$ region in $B$. rapa [31]. Although information on QTL regions and linkage markers in radish has been reported, no relevant information on the candidate resistance genes is available. In addition to $\mathrm{Crr} 1$ and $\mathrm{Crr} 3$, the $\mathrm{CRa}$ gene deserves increased attention because it confers resistance to pathotypes 2 and 4 , which are the predominant P. brassicae races in China $[8,23]$.

Compared with Brassica cultivars, a greater number of radish cultivars and lines are highly resistant to the clubroot pathogen [25,32]. However, some Chinese radish cultivation types, such as red-fleshed 'Xinlimei', lack CR genes. In this study, 95 radish inbred lines were evaluated and screened for clubroot resistance. The crucial resistance genes were identified using a homolog-based cloning method, and molecular markers were developed to assist in the introduction of the resistance genes into clubroot-susceptible radish cultivars by backcrossing. The results will be useful for marker-assisted breeding of clubroot-resistant cultivars to reduce disease-related yield loss in radish.

\section{Materials and Methods}

\subsection{Plant Materials and P. brassicae Inoculation}

Chinese cabbage clubroots infected with $P$. brassicae were collected from a farm in Changyang, Hubei province, China, and were stored at $-20{ }^{\circ} \mathrm{C}$ for use as inoculum in this study. The pathotype was identified as race 4 based on the Williams differential 
classification system $[33,34]$. The resting spore inoculum was extracted from the sampled clubroots using the following protocol. The clubroots were homogenized with a 1.5-times volume of sterile distilled water in a blender. The homogenate was filtered through four layers of cheesecloth and the suspension was centrifuged at $500 \times g$ for $5 \mathrm{~min}$. The resting spore concentration in the supernatant was adjusted to approximately $2 \times 10^{8}$ spores $/ \mathrm{mL}$ with sterile water (modified from) [28]).

Ninety-five radish inbred lines originating from China, Japan, South Korea, and Europe were evaluated for clubroot resistance in a greenhouse during October and November 2018 (Supplementary Table S1). Disease-resistant lines were further tested in 2019 and 2020. One pre-germinated seed was sown in a $7 \mathrm{~cm} \times 7 \mathrm{~cm} \times 10 \mathrm{~cm}$ plastic pot containing sterile peat-vermiculite-soil $(1: 1: 1, v / v / v)$ growing medium. The spore suspension $(1 \mathrm{~mL})$ was injected uniformly over each seed using a transferpettor before the seed was covered with growing medium. To ensure successful inoculation, after 1 week, the seedlings were inoculated by injecting $1 \mathrm{~mL}$ spore suspension around the stem base. Plants were grown at an average temperature of $18-25{ }^{\circ} \mathrm{C}$ under natural light in a greenhouse, and the germinated seeds or seedlings were kept moist. At 60 days after sowing, each radish seedling was uprooted, and the roots were washed and examined for clubroot symptoms. Symptoms were graded visually using the modified method of Kamei et al. [30] and Yang et al. [29]: grade 0 , no symptoms; grade 1, a few small, separate, globular clubs on lateral roots; grade 2, a few small clubs on the taproot; grade 3, obviously enlarged clubs on the taproot; and grade 4 , severe clubs on the taproot (Figure 1). The treatments were arranged in a completely randomized block design with three biological replicates and 10 seedlings for each replicate. The mean grade for 10 seedlings was calculated as the disease index (DI) for each breeding line. The resistance of each accession was evaluated according to the following criteria: immune: DI $=0$; highly resistant: $0<\mathrm{DI} \leq 1$; slightly susceptible: $1<\mathrm{DI} \leq 2$; moderately susceptible: $2<\mathrm{DI} \leq 3$; highly susceptible: $3<\mathrm{DI} \leq 4$.

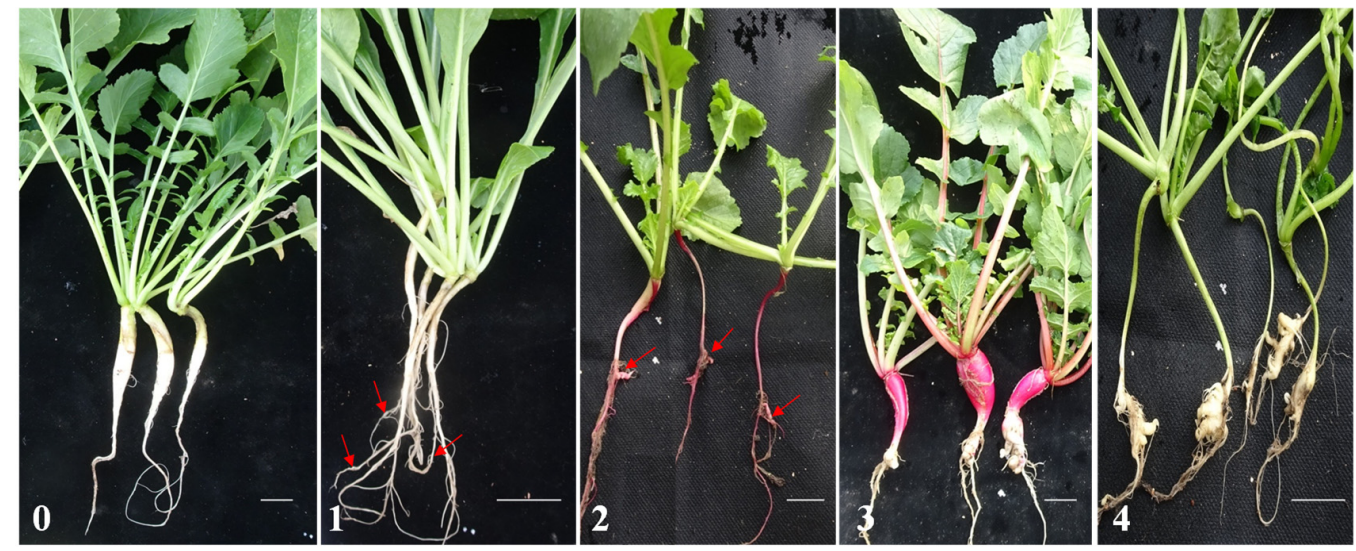

Figure 1. Grades of clubroot symptoms in radish seedlings at 60 days after inoculation with P. brassicae. Disease symptoms were assessed according to a five-point scale ranging from 0 (no symptoms) to 4 (severe clubroots). Scale bar $=2 \mathrm{~cm}$. Arrows indicate a few small clubs on lateral roots.

\subsection{DNA Extraction, Gene Cloning, and Sequencing Analysis}

DNA was extracted from young leaves using a modified cetyltrimethylammonium bromide method [35]. Primers for PCR amplification of the CRa, Crr1, and Crr3 QTLs were designed based on sequences in the radish XYB36-2 reference genome [36]. Details regarding the primers and the expected size of the amplified fragments are listed in Supplementary Table S2. Each PCR was performed in a $50 \mu \mathrm{L}$ volume containing $100 \mathrm{ng}$ DNA, $5 \mu \mathrm{L}$ of $10 \times$ PCR buffer (containing $\left.\mathrm{MgCl}_{2}\right), 1 \mu \mathrm{L}$ each primer $(10 \mu \mathrm{M}), 4 \mu \mathrm{L} \mathrm{dNTPs}(10 \mathrm{mM})$, 2.0 U Taq DNA polymerase, and $\mathrm{ddH}_{2} \mathrm{O}$ (Biomedical Technology Co., Beijing, China). The PCR amplification was conducted with a MyCycler system (Bio-Rad Laboratories, Hercules, CA, USA) with the following program: $95^{\circ} \mathrm{C}$ for $2 \mathrm{~min}$; 35 cycles of $95^{\circ} \mathrm{C}$ for $30 \mathrm{~s}, 58$ ${ }^{\circ} \mathrm{C}$ for $30 \mathrm{~s}$, and $72{ }^{\circ} \mathrm{C}$ for $2 \mathrm{~min}$; and $72{ }^{\circ} \mathrm{C}$ for $5 \mathrm{~min}$. The amplified fragments were 
purified and ligated into the pMD18-T vector. The resulting recombinant plasmids were inserted into Escherichia coli (strain $\mathrm{DH} 5 \alpha$ ) competent cells and then sequenced (Sangong, Shanghai, China).

The sequences of PCR fragments were assembled with the DNAStar program. Multiple sequence alignment and phylogenetic analysis were conducted with CLUSTAL $X$ (version 1.83) and MEGA4.0 software, respectively. Homology and synteny analysis of clubroot resistance genes $C R a, C r r 1$, and $C r r 3$ in B. rapa and $R$. sativus was performed using the minimap2 program with a set of default parameters on 15 April 2021 (https://github.com/lh3/minimap2, [37]).

\section{Results}

\subsection{Evaluation of Radish Inbred Lines for Resistance to P. brassicae Race 4}

A total of 95 radish inbred lines were evaluated for resistance to $P$. brassicae race 4 . Twenty-seven lines were immune $(\mathrm{DI}=0)$ and six lines were highly resistant $(0<\mathrm{DI}<1)$ to the pathotype. Most of the resistant lines originated from Japan, and some disease-resistant white radish lines were from South Korea and southeast China (CR-38, CR-42, CR-46, CR-49 and CR-51; Supplementary Table S1). The majority of the tested lines were susceptible to $P$. brassicae: 21 lines were slightly susceptible $(1<\mathrm{DI} \leq 2), 21$ lines showed moderate susceptibility $(2<\mathrm{DI} \leq 3)$, and 20 lines were highly susceptible $(3<\mathrm{DI} \leq 4)$ (Table 1$)$. The susceptible lines mainly originated from China (33 accessions, 82.5\%) and South Korea (19 accessions, 57.56\%). In particular, all lines of the green-skin, red-skin, and 'Xinlimei' types from China showed moderate to high susceptibility, whereas five Japanese lines showed only slight susceptibility (Table 1, Supplementary Table S1).

Table 1. Summary of resistance to $P$. brassicae race 4 in radish lines of different countries.

\begin{tabular}{|c|c|c|c|c|c|c|}
\hline Provenance & Total & $\begin{array}{l}\text { Immune } \\
\mathrm{DI}=0\end{array}$ & $\begin{array}{l}\text { Highly Resistant } \\
0<\mathrm{DI} \leq \mathbf{1}\end{array}$ & $\begin{array}{c}\text { Slightly Susceptible } \\
1<\mathrm{DI} \leq 2\end{array}$ & $\begin{array}{c}\text { Moderately Susceptible } \\
2<\mathrm{DI} \leq 3\end{array}$ & $\begin{array}{c}\text { Highly Susceptible } \\
3<\mathrm{DI} \leq 4\end{array}$ \\
\hline China & 40 & 6 & 1 & 3 & 16 & 14 \\
\hline South Korea & 33 & 11 & 3 & 8 & 5 & 6 \\
\hline Japan & 16 & 10 & 1 & 5 & 0 & 0 \\
\hline Other & 6 & 0 & 1 & 5 & 0 & 0 \\
\hline Total & 95 & 27 & 6 & 21 & 21 & 20 \\
\hline
\end{tabular}

\subsection{Homology of Clubroot Resistance Genes and Co-Segregation Analysis of Haplotype and Clubroot Resistance}

Considering that radish is a close relative of Brassica, the QTL region of CR genes showed collinearity and may exhibit a common ancestral relationship with CR genes of Brassica species [30,31]. Therefore, based on the radish reference genome (XYB36-2), we conducted a BLAST search and aligned the gene and flanking regions of Crr1 (AB605024), $\mathrm{CRa}$ (AB751516), and Crr3 (marker interval: BrSTS-54-BrSTS-78) from Chinese cabbage. The homolog of Crr1 was Rsa10003637 on chromosome R08 of radish, with $91.69 \%$ sequence identity (Table 2). Interestingly, the aligned homologous region of CRa contained three tandem disease-resistance genes (Rsa10025569, Rsa10025570, and Rsa10025571) on chromosome R04: 5204303-5232999. The sequence for Rsa10025570 was incomplete; the sequence identities of $C R a$ with Rsa10025569 and Rsa10025571 were $86.79 \%$ and $85.93 \%$, respectively (Table 2). The homolog of Crr3 was located on chromosome R05 of radish. In addition, synteny analysis of the flanking nucleotide sequence $( \pm 20-30 \mathrm{~kb})$ of the clubroot resistance gene or QTL markers further confirmed the position of the homolog in the radish genome (Supplementary Figures S1-S4). 
Table 2. Homology and synteny analysis of the clubroot resistance genes Crr1, $C R a$, and Crr3 QTL in B. rapa and $R$. sativus.

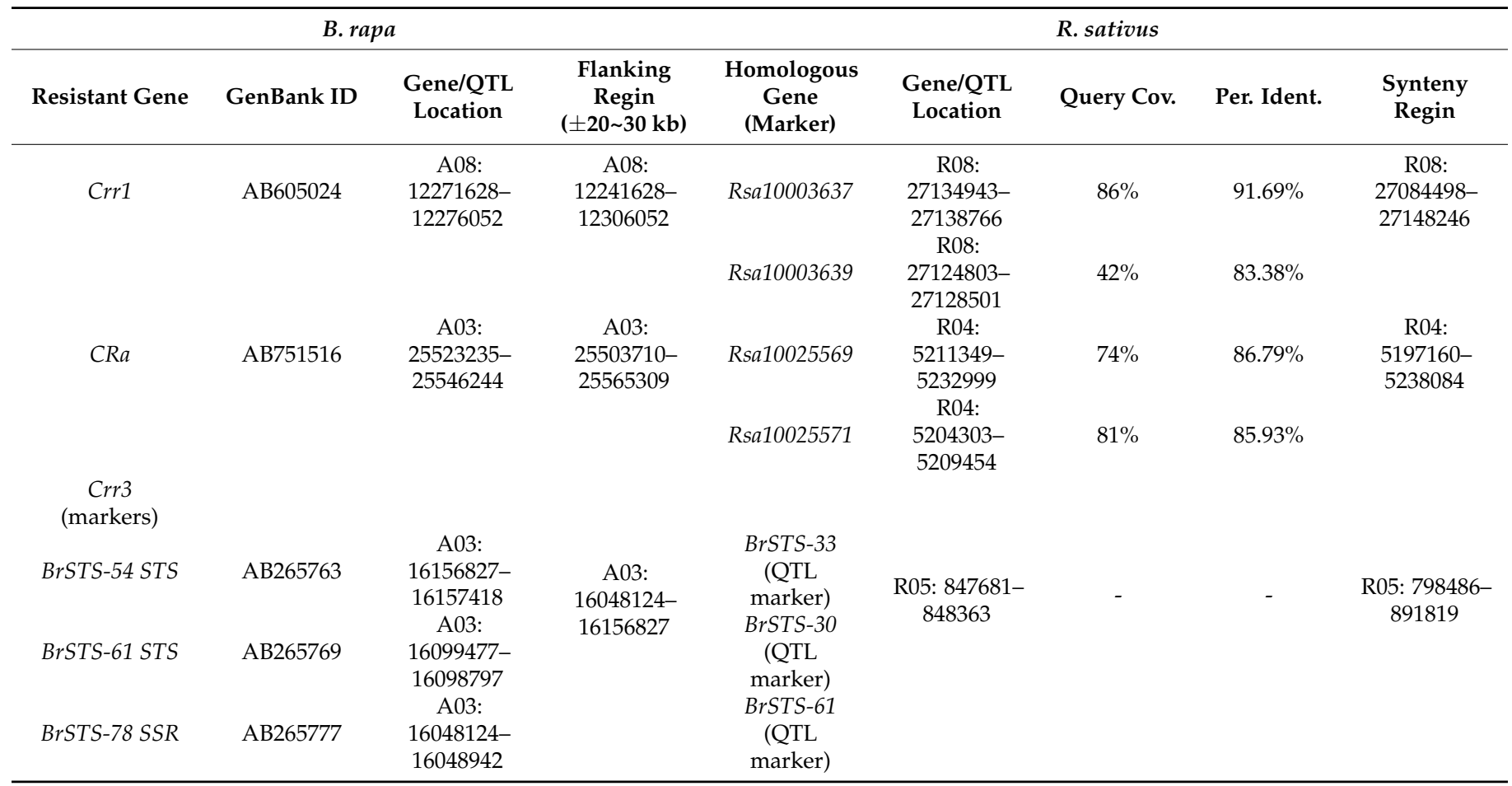

Note: Gene location information origin from B. rapa genome (v3.0, [38]) and radish genome XYB36-2 [36].

To evaluate the relationship between the genotype of the resistance genes (Rsa10003637, Rsa10025569/Rsa10025571, and Crr3 QTLs) and degree of clubroot resistance, we developed nine functional markers for genotyping using six resistant lines and ten susceptible lines (Figure 2, Supplementary Table S3). The Rsa10003637 gene comprised four haplotypes (H1 to H4) among the 16 test lines based on three functional markers. Except for haplotype H1, the other haplotypes were present in both resistant and susceptible materials. Therefore, no significant correlation between the Rsa10003637 genotype and degree of clubroot resistance was observed among the test lines. Rsa10025569 comprised five haplotypes (H1 to H5) among the 16 test lines. It is worth noting that haplotype H3 was present in only three clubroot-resistant lines, which differed from the haplotypes of all ten clubroot-susceptible test lines. The results suggested that $\mathrm{H} 3$ can be used as a clubroot-resistant haplotype, and the percentage coincidence between resistance degree and genotype may attain $81.25 \%$ (13/16 lines). The markers BrSTS-30 (AfaI CAPs), BrSTS-61 (HinfI CAPs), and BrSTS-33 (Hinf I CAPs) for the major clubroot-resistance Crr3 QTL region in radish (Crs1; Kamei et al. 2010) showed no polymorphism or did not co-segregate with the response of clubroot pathogens among the 16 inbred lines. Interestingly, the resistant inbred line CR-79 was indicated to be distinctive in that the Rsa10003637 and Rsa10025569 genotypes were unique (Figure 2, Supplementary Table S3). 


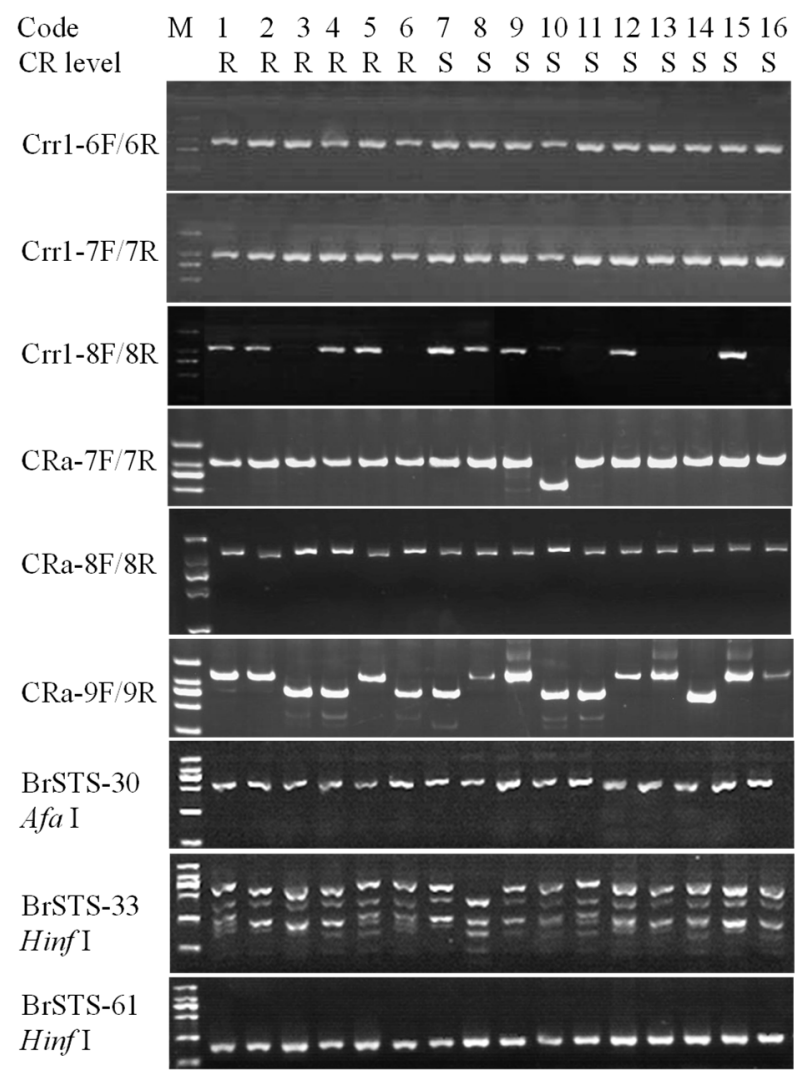

Figure 2. Functional markers for genotyping using six clubroot-resistant lines and ten clubrootsusceptible lines of radish. $\mathrm{R}$ and $\mathrm{S}$ indicate clubroot-resistant and clubroot-susceptible lines, respectively. M: DNA marker. Bands indicate 2000 bp, 1000 bp, 750 bp, 500 bp, 300 bp, 200 bp, and 100 bp from top to bottom. Codes 1-16: CR-79, CR-59, CR-60, CR-88, CR-75, CR-78, CR-4, CR-6, CR-35, CR-34, CR-28, CR-10, CR-12, CR-19, CR-22, and CR-23.

\subsection{Cloning of the RsCRa Allele in Clubroot-Susceptible and-Resistant Radish Inbred Lines}

A series of primers (Supplementary Table S2) were designed based on the sequence in the radish XYB36-2 reference genome for amplification of Rsa10025569 and Rsa10025571 as candidate genes for RsCRa. The lines CR-60 (YR-kurama) and CR-88 (ShirokubiMiyashige) were selected as clubroot-resistant genotypes, and CR-10 (Chunlihong) and CR-35 (Yangzhou Yuanbai) were selected as clubroot-susceptible genotypes for allelic gene cloning. First, we analyzed the sequence variation of Rsa10025569. For the resistant lines CR-60 and CR-88, a $2801 \mathrm{bp}$ fragment was amplified and spliced using the primer sets Cra-7F/7R, Cra-8F/8R, and Cra-9F/9R, including part of the NBS and LRR domains. We did not obtain a complete amplified fragment of the first exon and intron and speculated that a large retrotransposon-like sequence may be present in the first intron, similar to the Chinese cabbage lines Q5 and Chiifu-401-42 [13]. For the susceptible lines CR-10 and CR-35, a 5739 bp fragment was amplified and spliced by PCR with six primer sets. The sequence identities with the amplified region of the resistant lines were $92.47 \%$, except for a $699 \mathrm{bp}$ insertion at the end of the fourth exon. The $699 \mathrm{bp}$ insertion just broke the stop condon and caused an extension of 29 amino acids. The sequence from clubroot-resistant lines and clubroot-susceptible lines showed $87.32 \%$ and $87.4 \%$ similarity, respectively, to the CRa gene of B. rapa (Figure 3, Supplementary Table S4). 


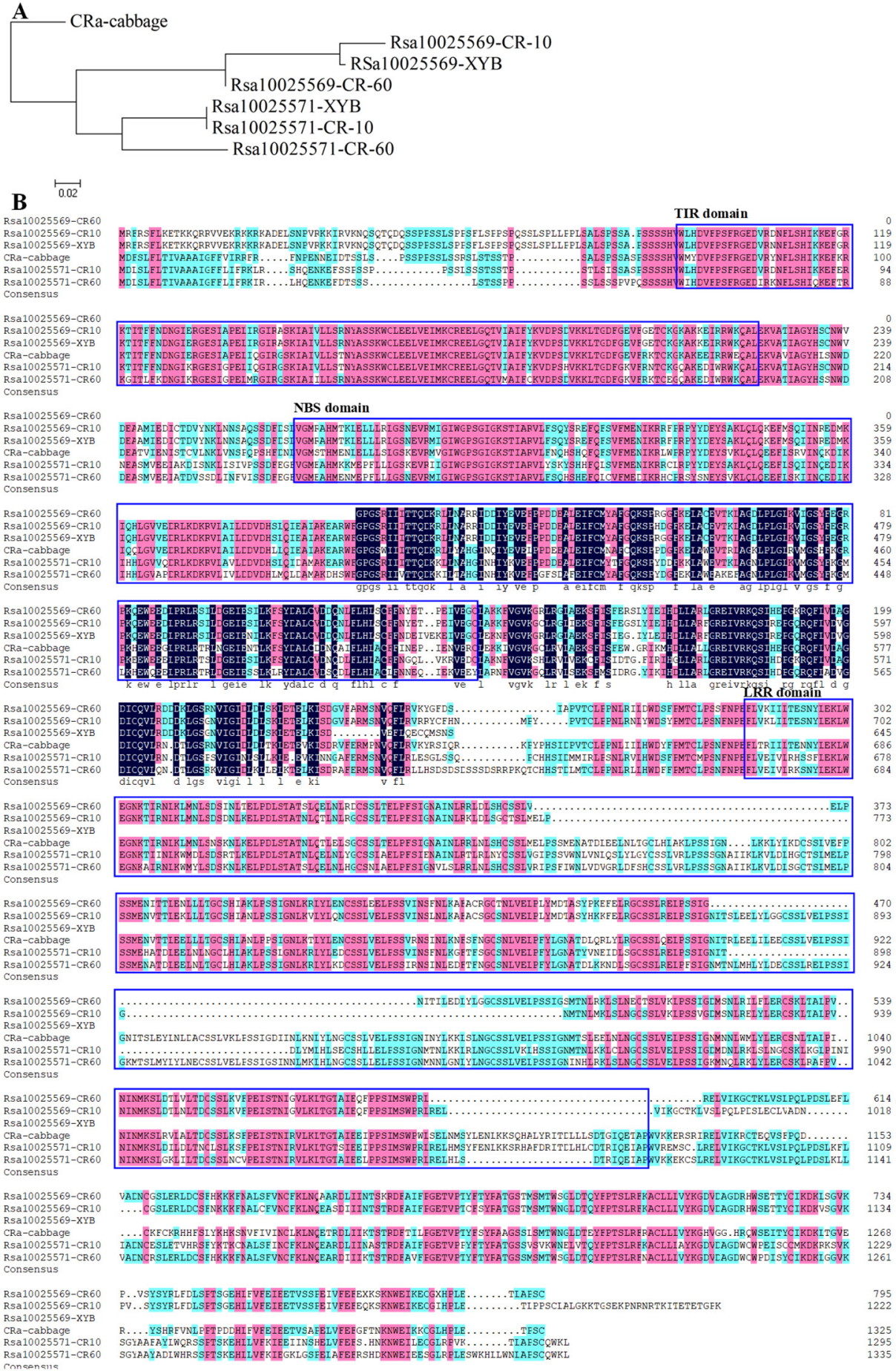

Figure 3. Phylogenetic relationships and amino acid sequence alignment of the Rsa10025569 and Rsa10025571 genes of radish. (A) Phylogenetic tree for Rsa10025569 and Rsa10025571 of radish lines CR-10, CR-60, and XYB36-2, and the CRa gene of Brassica rapa (GenBank: AB751516). Scale bar indicates nucleotide substitutions per site. (B) Alignment of CRa, Rsa10025569, and Rsa10025571 protein sequences in the CR-60, CR-10, and XYB36-2 reference genome. The CRa-cabbage sequences were downloaded from GenBank (accession no. BAN04700). Blue boxes indicate TIR-NBS-LRR domains.

And then, Rsa10025571 was cloned, which was a tandem disease-resistance gene in the $R_{s C R} a$ locus. The sequence of the PCR product (4767 bp) amplified from the clubrootsusceptible lines CR-10 and CR-35 showed 100\% similarity to that of XYB36-2. The similarity between the amplified sequences from the clubroot-resistant lines CR-60 and CR-88 
(5068 bp) and the homologous sequence in clubroot-susceptible lines was $86.95 \%$. The sequence also contained the TIR-NBS-LRR domains by linear comparison with the CRa gene of B. rapa (Figure 3, Supplementary Table S5).

\subsection{Verification of Markers for RsCRa and Marker-Assisted Backcrossing for Selection of Clubroot Resistance}

To further confirm the utility of the Rsa10025569 loci for molecular marker-assisted selection of clubroot resistance, the marker pair CRa-9F/9R was used for genotyping of $\mathrm{BC}_{1} \mathrm{~F}_{1}$ populations derived from the crosses $(\mathrm{CR}-88 \times \mathrm{CR}-10) \times \mathrm{CR}-10$. Among the 77 progenies infected with $P$. brassicae, the number of individuals identified as immune, highly resistant, slightly susceptible, moderately susceptible, and highly susceptible was 7, 10, 10, 36 , and 14, respectively. Co-segregation analysis of the markers CRa-9F/9R and clubroot resistance revealed that the 17 immune or highly resistant individuals had a CRa-9F/9R heterozygous genotype (1500 bp/750 bp), whereas the most highly susceptible 14 plants had the same genotype as the clubroot-susceptible line CR-10 (1500 bp/1500 bp, Figure 4). The correlation value was $89.61 \%$ between the genotype of the markers CRa-9F/9R and clubroot resistance in all $77 \mathrm{BC}_{1} \mathrm{~F}_{1}$ progenies. These data indicated that molecular markerassisted selection of clubroot-resistant lines was feasible.

A

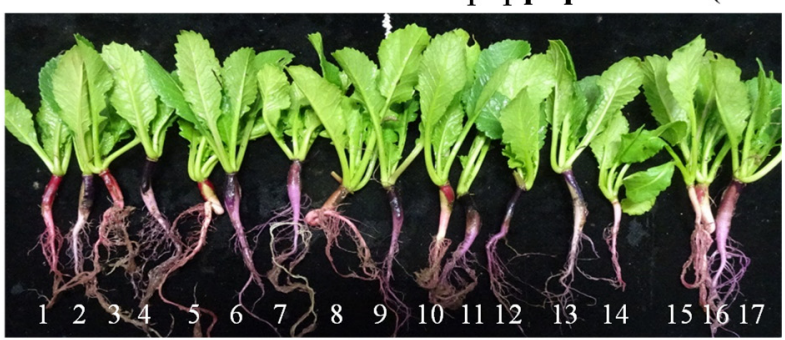

clubroot-resistant

B

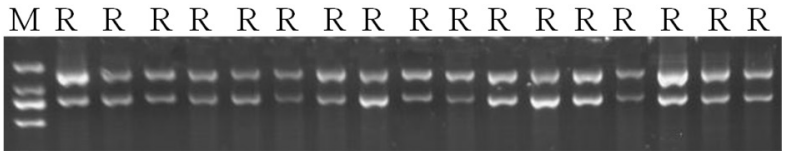

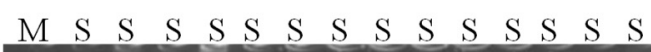

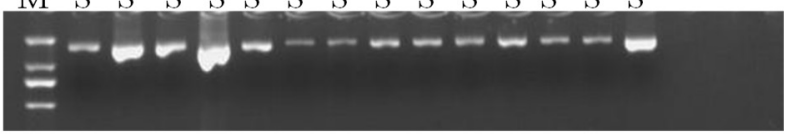

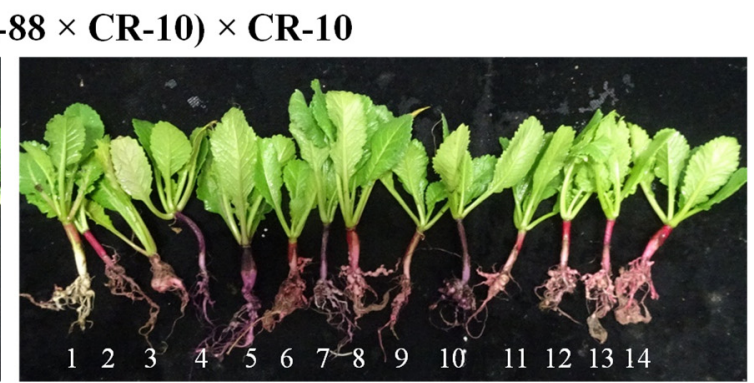

clubroot-susceptible

C

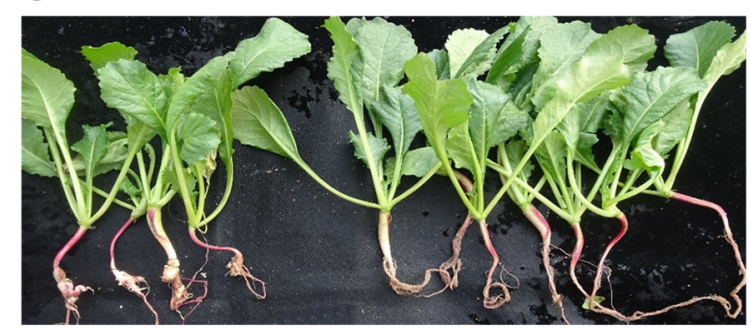

CR-10 Individuals of $\mathrm{BC}_{2} \mathrm{~F}_{3}$

Figure 4. Validation of PCR markers using $\mathrm{BC}_{1} \mathrm{~F}_{1}$ populations derived from the crosses $(\mathrm{CR}-88 \times$ CR-10) $\times$ CR-10. (A) Clubroot symptoms of individual plants at 60 days after first infection with P. brassicae. Seventeen immune or highly resistant individuals and fourteen of the most highly susceptible plants. (B) Results of PCR amplification. S and R indicate clubroot-susceptible and clubroot-resistant lines, respectively. M: DNA marker 2000 bp. (C) Clubroot symptoms of individuals derived from $\mathrm{CR}-10$ and individuals of $\mathrm{BC}_{2} \mathrm{~F}_{3}$.

Based on the above research, molecular marker-assisted selection was used to transfer disease resistance genes to susceptible varieties (Figure 5). Three clubroot-resistant individuals were selected as the female parent from the $\mathrm{BC}_{1} \mathrm{~F}_{1}$ populations and crossed with the recurrent parent $(\mathrm{CR}-10)$ to generate the $\mathrm{BC}_{2} \mathrm{~F}_{1}$ populations. At the seedling stage, ten individuals with the CRa-9F/9R heterozygous genotype (1500 bp/750 bp) were selected from $24 \mathrm{BC}_{2} \mathrm{~F}_{1}$ plants, and large-scale $\mathrm{BC}_{2} \mathrm{~F}_{2}$ populations were generated through self-pollination. Agronomic traits of $426 \mathrm{BC}_{2} \mathrm{~F}_{2}$ progenies were evaluated in autumn, and 12 individuals with CRa-9F/9R homozygous genotypes (750 bp/750 bp) and crucial agronomic traits similar to those of the reincarnation parents were selected for further selfing. A 
new CR germplasm of Xinlimei was obtained and the clubroot resistance was significantly enhanced compared with the control (Figure 4C).

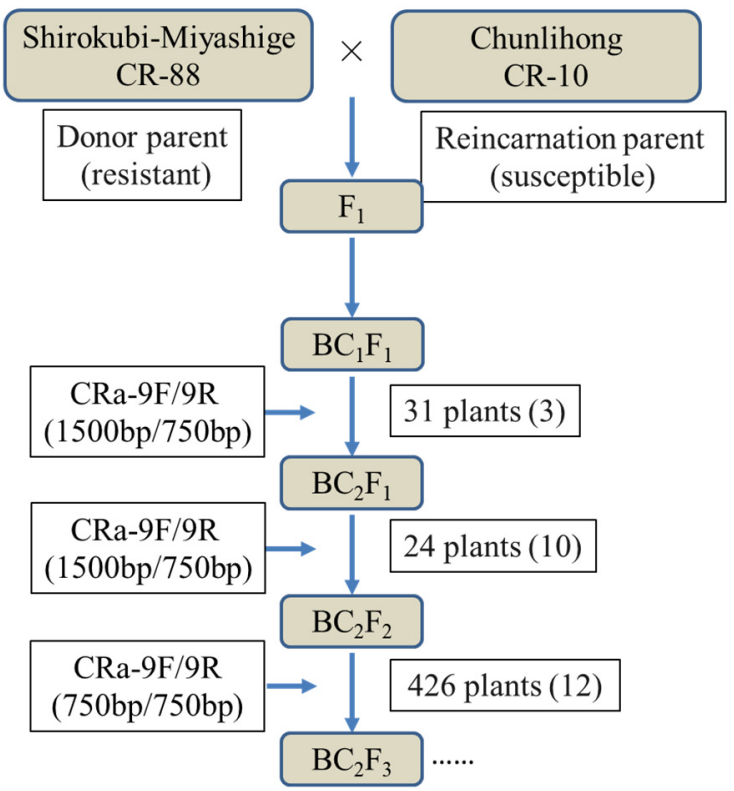

Figure 5. Schematic diagram of backcrossing combined with molecular marker-assisted selection of a CR gene. The value in parentheses is the number of selected individuals with CRa-9F/9R resistant genotypes.

\section{Discussion}

We evaluated the clubroot resistance of 95 radish accessions. Thirty-three lines were immune or strongly resistant to P. brassicae race 4, of which 26 lines (78\%) were of foreign origin. In addition, 30 of the 41 inbred lines $(73.17 \%)$ that originated from Chinese cultivars were moderately to highly susceptible to clubroot (Table 1). All lines of the redskin, green-skin, and 'Xinlimei' types were susceptible to P. brassicae, consistent with the findings of Yoshikawa [39]. Rowe et al. reported that most US radish accessions tested were moderately to highly susceptible to clubroot, whereas all Japanese and many Dutch cultivars showed absolute resistance [28]. A recent study reported that the majority of the tested radish germplasm was susceptible to the clubroot pathogen, including 81 susceptible and 204 highly susceptible accessions based on the DIs of an extensive source collection of 349 accessions. Exotic radish germplasm has a higher degree of resistance to clubroot disease than local Chinese radish cultivars [29]. However, early studies indicated that the majority of radish cultivars and inbred lines possess a high degree of resistance [32,40], which may reflect differences in the tested germplasm and pathogen races.

The main artificial methods of inoculating cruciferous crops with $P$. brassicae comprise treatment with resting spore-inoculated soil, injection, soaking, or dipping the root in a spore suspension [41]. Radish develops an enlarged taproot with few fibrous roots, which may result in infection symptoms that are initially inconspicuous and only subsequently become visible. Precise and reliable artificial inoculation of radish with P. brassicae is not straightforward compared with inoculation of other cruciferous crops [1,29]. Yang et al. evaluated the clubroot resistance of a radish germplasm collection using a two-stage inoculation method combining bud injection and injury to the seedling root, which achieved superior stability and accuracy of infection compared to a single-inoculation method [29]. In the present study, we improved the inoculation method by increasing the resting spore concentration $\left(2 \times 10^{8}\right.$ spores $\left./ \mathrm{mL}\right)$, performing two-stage inoculation (at seed sowing and 1 week after sowing), and delaying the assessment of symptoms (60 days after sowing). In addition, we performed two or three repeat assessments of disease-resistant inbred lines to overcome the influence of environmental or plant physiological factors. 
At present, it is difficult to control clubroot disease with chemical fungicides and cultivation management. Development of disease-resistant cultivars is the most effective strategy for disease control. However, clubroot-resistant radish cultivars in China remain scarce, especially green-skin, red-skin, and Xinlimei types, for which no resistant lines were identified. Therefore, our main objective is to improve the degree of clubroot resistance of radish cultivars by backcrossing and marker-assisted selection using immune or highly resistant radish accessions. In this study, we obtained a new CR germplasm of Xinlimei by transferring disease resistance genes into susceptible varieties. Furthermore, multiple resistance genes must be accumulated into a single cultivar for broad-spectrum and longerlasting clubroot resistance. Three $C R$ genes $(C R a, C R k$, and $C R c)$ were accumulated in Chinese cabbage through marker-assisted selection [42]. Similarly, the NARO Institute of Vegetable and Tea Science developed a Chinese cabbage cultivar with strong resistance to clubroot disease by accumulating CR genes located at the Crr1, Crr2, and CRb loci. Combinations of different CR genes exhibit enhanced resistance to clubroot disease [43]. Although we evaluated the resistance of 95 radish inbred lines to P. brassicae race 4 , the degree of resistance to other races remains unclear. More precise identification of resistance is required using different pathotypes, and CR genes require characterization and cloning in the future.

Many clubroot-resistant cultivars of radish and Brassica crops have been bred [42,44-49]. However, two potential risks remain. One is that the resistance source in Brassica is extremely narrow and most CR genes originate from European fodder turnip [43], which may result in deficiency of CR genes when resistance is overcome. In addition, the resistance of clubroot-resistant cultivars weakens or disappears with time owing to race-specific resistance and extensive pathogenic variation. Therefore, it is essential to screen resistance sources extensively and enrich disease-resistance genes. In the present study, we identified 33 immune or strongly resistant radish lines, which may harbor different CR genes based on the results of molecular marker genotyping (Figure 2). Considering that radish is a close relative of Brassica [50], the CR genes may exhibit a common ancestral relationship with CR genes of Brassica species [30,31]. Thus, resistance genes from radish transferred to Brassica species through distant hybridization or protoplast fusion are expected to show considerable potential for conferring disease resistance. The transfer of CR genes to Brassica has been attempted previously [51,52]. Akaba et al. evaluated nine types of B. napus-R. sativus monosomic addition lines (MALs) and observed that the C-type MAL showed strong resistance to clubroot disease [53].

Most disease-resistance $(\mathrm{R})$ genes encode proteins that carry a nucleotide binding site (NBS) in the central region and a leucine-rich repeat (LRR) domain at the C-terminus. In general, the LRR protein can recognize pathogen signals and the NBS domain regulates activation of the plant immune system [54]. Hundreds of NBS-LRR genes are present in plant genomes [55]. The $R$ genes have been comprehensively identified in radish and several species of Brassica [56-58]. Thirty-eight NBS-encoding sequences were identified from the radish leaf transcriptome by bioinformatic analysis [58]. Complex mixed clusters of NBSLRR loci are a notable feature derived from gene duplication events and frequently undergo rearrangement [59]. In the present study, $R_{s} C R a$ loci also contained three tandem repeat genes (Rsa10025569, Rsa10025570, and Rsa10025571), although Rsa10025570 contained an incomplete NBS-LRR structure (Figure 3). RsCra gene haplotypes may be more abundant, except for CR-88 and CR-10 types, considering that we did not sequence all lines. In addition, the association between degree of clubroot resistance and the other haplotypes of CR genes requires further analysis.

Supplementary Materials: The following supporting information can be downloaded at: https: / / www.mdpi.com/article/10.3390/agronomy12030554/s1, Table S1: Response of 95 radish inbred lines to $P$. brassicae race 4 in a greenhouse, Table S2: Homology and synteny analysis of the clubroot resistance genes and QTL Crr1, $C R a$, and $C r r 3$ in B. rapa and $R$. sativus, Table S3: Clubroot resistance to $P$. brassicae race 4 and the genotype of $C r r 1, C r r 3$, and $C R a$, Table S4: Primers used in this study, Table S5: Alignment of CRa, Rsa10025569, and Rsa10025571 sequences in the CR-60 and CR-10 lines, 
and the XYB36-2 reference genome. Figure S1: Collinearity between the clubroot resistance genes and flanking region of B. rapa and the radish 'XYB36-2' genome, Figure S2: Collinearity between the Crr3 gene and flanking region of $B$. rapa and the radish chromosome R05 (798486 bp-891819 bp), Figure S3: Collinearity between the $\mathrm{Crr} 1$ gene and flanking region of $B$. rapa and the radish chromosome R08 (27084498 bp-27148246 bp), and Figure S4: Collinearity between the CRa gene and flanking region of B. rapa and the radish chromo-some R04 (5197160 bp-5238084 bp).

Author Contributions: Conceptualization, L.Z. and Q.W.; methodology, Y.W. and Q.W.; resources, L.Z.; investigation, Z.Z. and H.Q.; formal analysis, Y.W. and L.Z.; software, Q.W.; writing-original draft preparation, Q.W.; writing —review and editing, L.Z.; supervision, L.Z.; funding acquisition, L.Z. and Q.W. All authors have read and agreed to the published version of the manuscript.

Funding: This work was supported by grants from the Innovation and Development Program of Beijing Vegetable Research Center (KYCX202001-05), the Construction Program of Science and Technology Innovation Capacity of Beijing Academy of Agriculture and Forestry Sciences (Grant Number KJCX20210420, KJCX20200113).

Institutional Review Board Statement: Not applicable.

Informed Consent Statement: Not applicable.

Data Availability Statement: Data are contained within the article or Supplementary Materials.

Acknowledgments: We are grateful to Honghe Sun from National Engineering Research Center for improving the experimental scheme in this study.

Conflicts of Interest: The authors declare no conflict of interest.

\section{References}

1. Hirai, M. Genetic analysis of clubroot resistance in Brassica crops. Breed. Sci. 2006, 56, 223-229. [CrossRef]

2. Dixon, G.R. The occurrence and economic impact of Plasmodiophora brassicae and clubroot disease. J. Plant Growth Regul. 2009, 28, 19. [CrossRef]

3. Strelkov, S.E.; Dixon, G.R. Clubroot (Plasmodiophora brassicae) on canola and other Brassica species-Disease development, epidemiology and management. Can. J. of Plant Patho. 2014, 36 (Suppl. S1), 1-4. [CrossRef]

4. Kageyama, K.; Asano, T. Life cycle of Plasmodiophora brassicae. J. Plant Growth Regul. 2009, 28, 203-211. [CrossRef]

5. Rolfe, S.A.; Strelkov, S.E.; Links, M.G.; Clarke, W.E.; Robinson, S.J.; Djavaheri, M.; Malinowski, R.; Haddadi, P.; Kagale, S.; Parkin, I.A.P. The compact genome of the plant pathogen Plasmodiophora brassicae is adapted to intracellular interactions with host Brassica spp. BMC Genom. 2016, 17, 272. [CrossRef]

6. Huang, Q.W.; Ou, Y.L.; Wang, Y.J. Occurrence and prevention of clubroot disease on cruciferous crops in Jiangxi. Bull. Plant Prot. 1955, 8, 1-4. (In Chinese)

7. Wang, J.; Huang, Y.; Li, X.L.; Li, H.Z. Reseach progress in clubroot of crucifers. Plant Prot. 2011, 37, $153-158$.

8. Chai, A.L.; Xie, X.W.; Shi, Y.X.; Li, B.J. Research status of clubroot (Plasmodiophora brassicae) on cruciferous crops in China. Can. J. Plant Pathol. 2014, 36, 142-153. [CrossRef]

9. Shen, X.Q.; Nie, K.; Wu, Q.; Zhang, Y.G.; Meng, X.H. Initial research report on differentiation identification of Chinese cabbage clubroot main physiological races. Chin. Veg. 2009, 8, 59-62. (In Chinese)

10. Liu, Y.; Luo, Y.F.; Huang, X.Q.; Zhang, L.; Liu, H.Y. Research progress of differential systems for physiological races of Plasmodiophora brassicae Wor. Agric. Sci. Technol. 2012, 13, 2236-2241.

11. Pang, W.X.; Liang, Y.; Zhan, Z.X.; Li, X.N.; Piao, Z.Y. Development of a Sinitic clubroot differential set for the pathotype classification of Plasmodiophora brassicae. Front. Plant Sci. 2020, 11, 568771. [CrossRef] [PubMed]

12. Matsumoto, E.; Yasui, C.; Ohi, M.; Tsukada, M. Linkage analysis of RFLP markers for clubroot resistance and pigmentation in Chinese cabbage. Euphytica 1998, 104, 79-86. [CrossRef]

13. Ueno, H.; Matsumoto, E.; Aruga, D.; Kitagawa, S.; Matsumura, H.; Hayashida, N. Molecular characterization of the CRa gene conferring clubroot resistance in Brassica rapa. Plant Mol. Biol. 2012, 80, 621-629. [CrossRef]

14. Hatakeyama, K.; Niwa, T.; Kato, T.; Ohara, T.; Kakizaki, T.; Matsumoto, S. The tandem repeated organization of NB-LRR genes in the clubroot-resistant CRb locus in Brassica rapa L. Mol. Genet. Genom. 2017, 292, 397-405. [CrossRef] [PubMed]

15. Suwabe, K.; Tsukazaki, H.; Iketani, H.; Hatakeyama, K.; Fujimura, M.; Nunome, T.; Fukuoka, H.; Matsumoto, S.; Hirai, M. Identification of two loci for resistance to clubroot (Plasmodiophora brassicae Woronin) in Brassica rapa L. Theor. Appl. Genet. 2003, 107, 997-1002. [CrossRef] [PubMed]

16. Suwabe, K.; Tsukazaki, H.; Iketani, H.; Hatakeyama, K.; Kondo, M.; Fujimura, M.; Nunome, T.; Fukuoka, H.; Hirai, M.; Matsumoto, S. Simple sequence repeat-based comparative genomics between Brassica rapa and Arabidopsis thaliana: The genetic origin of clubroot resistance. Genetics 2006, 173, 309-319. [CrossRef] 
17. Hatakeyama, K.; Suwabe, K.; Tomita, R.N.; Kato, T.; Nunome, T.; Fukuoka, H.; Matsumoto, S. Identification and characterization of Crr1a, a gene for resistance to clubroot disease (Plasmodiophora brassicae Woronin) in Brassica rapa L. PLoS ONE 2013, 8, e54745. [CrossRef]

18. Hirai, M.; Harada, T.; Kubo, N.; Tsukada, M.; Suwabe, K.; Matsumoto, S. A novel locus for clubroot resistance in Brassica rapa and its linkage markers. Theor. Appl. Genet. 2004, 108, 639-643. [CrossRef]

19. Saito, M.; Kubo, N.; Matsumoto, S.; Suwabe, K.; Tsukada, M.; Hirai, M. Fine mapping of the clubroot resistance gene, Crr3, in Brassica rapa. Theor. Appl. Genet. 2006, 114, 81-91. [CrossRef]

20. Sakamoto, K.; Saito, A.; Hayashida, N.; Taguchi, G.; Matsumoto, E. Mapping of isolate-specific QTL for clubroot resistance in Chinese cabbage (Brassica rapa L. ssp. pekinensis). Theor. Appl. Genet. 2008, 117, 759-767. [CrossRef]

21. Chen, J.; Jing, J.; Zhan, Z.; Zhang, T.; Zhang, C.; Piao, Z. Identification of novel QTLs for isolate-specific partial resistance to Plasmodiophora brassicae in Brassica rapa. PLoS ONE 2013, 8, e85307. [CrossRef] [PubMed]

22. Pang, W.; Liang, S.; Li, X.; Li, P.; Yu, S.; Lim, Y.P.; Piao, Z. Genetic detection of clubroot resistance loci in a new population of Brassica rapa. Hortic. Environ. Biotechnol. 2014, 55, 540-547. [CrossRef]

23. Pang, W.; Fu, P.; Li, X.; Zhan, Z.; Yu, S.; Piao, Z. Identification and mapping of the clubroot resistance gene CRd in Chinese cabbage (Brassica rapa ssp. pekinensis). Front. Plant Sci. 2018, 9, 653. [CrossRef] [PubMed]

24. Choi, S.R.; Oh, S.H.; Chhapekar, S.S.; Dhandapani, V.; Lee, C.Y.; Rameneni, J.J.; Ma, Y.; Choi, G.J.; Lee, S.S.; Lim, Y.P. Quantitative trait locus mapping of clubroot resistance and Plasmodiophora brassicae pathotype banglim-specific marker development in Brassica rapa. Int. J. Mol. Sci. 2020, 21, 4157. [CrossRef] [PubMed]

25. Diederichsen, E.; Frauen, M.; Linders, E.G.A.; Hatakeyama, K.; Hirai, M. Status and perspectives of clubroot resistance breeding in crucifer crops. J. Plant Growth Regul. 2009, 28, 265-281. [CrossRef]

26. Zhang, T.; Wu, D.; Zhao, Z.; Wang, Z.; Piao, Z.Y. Development of near isogenic lines for clubroot resistance in Chinese cabbage and their assessment. Mol. Plant Breed. 2012, 6, 722-730.

27. Fredua-Agyeman, R.; Yu, Z.; Hwang, S.F.; Strelkov, S.E. Genome-wide mapping of loci associated with resistance to clubroot in Brassica napus ssp. napobrassica (Rutabaga) accessions from Nordic Countries. Front. Plant Sci. 2020, 11, 742. [CrossRef]

28. Rowe, R.C. Evaluation of radish cultivars for resistance to clubroot (Plasmodiophora brassicae) race 6 for Midwestern United States. Plant Disease 1980, 64, 462-464. [CrossRef]

29. Yang, H.; Yuan, Y.; Wei, X.; Zhang, X.; Wang, H.; Song, J.; Li, X. A new identification method reveals the resistance of an extensive-source radish collection to Plasmodiophora brassicae race 4. Agronomy 2021, 11, 792. [CrossRef]

30. Kamei, A.; Tsuro, M.; Kubo, N.; Hayashi, T.; Wang, N.; Fujimura, T.; Hirai, M. QTL mapping of clubroot resistance in radish (Raphanus sativus L.). Theor. Appl. Genet. 2010, 120, 1021-1027. [CrossRef]

31. Gan, C.; Deng, X.; Cui, L.; Yu, X.; Yuan, W.; Dai, Z.; Yao, M.; Pang, W.; Ma, Y.; Yu, X.; et al. Construction of a high-density genetic linkage map and identification of quantitative trait loci associated with clubroot resistance in radish (Raphanus sativus L.). Mol. Breed. 2019, 39, 116. [CrossRef]

32. Scheijgrond, W.; Vos, H. Investigation on the susceptibility to club root. Euphytica 1954, 3, 125-139. [CrossRef]

33. Ning, Y.; Wang, Y.; Fang, Z.; Zhuang, M.; Zhang, Y.; Lv, H.; Liu, Y.; Li, Z.; Yang, L. Identification and characterization of resistance for Plasmodiophora brassicae race 4 in cabbage (Brassica oleracea var. capitata). Australas Plant Pathol. 2018, 47, 531-541. [CrossRef]

34. Williams, P.H. A system for the determination of races of Plasmodiophora brassicae that infect cabbage and rutabaga. Phytopathology $1966,56,624-626$.

35. Murray, H.; Thompson, W. Rapid isolation of high molecular weight plant DNA. Nucleic Acids Res. 1980, 8, 4321-4325. [CrossRef] [PubMed]

36. Zhang, X.H.; Yue, Z.; Mei, S.Y.; Qiu, Y.; Yang, X.H.; Chen, X.H.; Cheng, F.; Wu, Z.Y.; Sun, Y.Y.; Jing, Y.; et al. A de novo genome of a Chinese radish cultivar. Hort. Plant J. 2015, 1, 155-164.

37. Li, H. Minimap2: Pairwise alignment for nucleotide sequences. Bioinformatics 2018, 34, 3094-3100. [CrossRef]

38. Zhang, L.; Cai, X.; Wu, J.; Liu, M.; Grob, S.; Cheng, F.; Liang, J.; Cai, C.; Liu, Z.; Liu, B.; et al. Improved Brassica rapa reference genome by single-molecule sequencing and chromosome conformation capture technologies. Hortic. Res. 2018, 5, 50. [CrossRef]

39. Yoshikawa, H. Studies on breeding of clubroot resistance in cole crops (in Japanese with English summary). Bull. Natl. Res. Inst. Veg. Ornam. Plants Tea Jpn. Ser. A 1993, 7, 1-165.

40. Crute, I.R.; Gray, A.R.; Crisp, P.; Buczacki, S.T. Variation in Plasmodiophora brassicae and resistance to clubroot disease in brassicas and allied crops-A critical review. Plant Breed. Abstr. 1980, 50, 91-104.

41. Chen, X.; Wang, C.; Zhang, X.X.; Wang, S. The inoculation system of cabbage clubroot and Screening of resistant germplasm resources. Plant Prot. 2015, 41, 121-126.

42. Matsumoto, E.; Ueno, H.; Aruga, D.; Sakamoto, K.; Hayashida, N. Accumulation of three clubroot resistance genes through marker-assisted selection in Chinese cabbage (Brassica rapa spp. pekinensis). J. Jpn. Soc. Hortic. Sci. 2012, 81, 184-190. [CrossRef]

43. Mehraj, H.; Akter, A.; Miyaji, N.; Miyazaki, J.; Shea, D.J.; Fujimoto, R.; Doullah, M. Genetics of clubroot and fusarium wilt disease resistance in Brassica vegetables: The application of marker assisted breeding for disease resistance. Plants 2020, 9, 726. [CrossRef]

44. Horikoshi, N.; Tairako, K. Occurrence of clubroot in Japanese radish caused by Plasmodiophora brassicae Woronin in Fukushima. Annu. Rep. Plant Prot. North Jpn. 2002, 53, 58-60.

45. Piao, Z.Y.; Wu, D.; Wang, M.; Zhang, T. Marker-assisted selection of near isogenic lines for clubroot resistant gene in Chinese cabbage. Acta Hortic. Sin. 2010, 37, 1264-1272. 
46. Chu, M.; Yu, F.; Falk, K.C.; Liu, X.; Zhang, X.; Chang, A.; Peng, G. Identification of the clubroot resistance gene Rpb1 and introgression of the resistance into canola breeding lines using a marker-assisted approach. Acta. Hortic. 2013, 1005, 599-605. [CrossRef]

47. Tomita, H.; Shimizu, M.; Doullah, M.A.U.; Fujimoto, R.; Okazaki, K. Accumulation of quantitative trait loci conferring broadspectrum clubroot resistance in Brassica oleracea. Mol. Breed. 2013, 32, 889-900. [CrossRef]

48. Shah, N.; Sun, J.; Yu, S.; Yang, Z.; Wang, Z.; Huang, F.; Dun, B.; Gong, J.; Liu, Y.; Li, Y.; et al. Genetic variation analysis of field isolates of clubroot and their responses to Brassica napus lines containing resistant genes $C R b$ and $P b B a 8.1$ and their combination in homozygous and heterozygous state. Mol. Breed. 2019, 39, 153. [CrossRef]

49. Kawasaki, M.; Ohara, T.; Ishida, M.; Takahata, Y.; Hatakeyama, K. Development of novel clubroot resistant rapeseed lines (Brassica napus L.) effective against Japanese field isolates by marker assisted selection. Breed. Sci. 2021, 71, 528-537. [CrossRef]

50. Jeong, Y.M.; Kim, N.; Ahn, B.O.; Oh, M.; Chung, W.H.; Chung, H.; Jeong, S.; Lim, K.B.; Hwang, Y.J.; Kim, G.B. Elucidating the triplicated ancestral genome structure of radish based on chromosome-level comparison with the Brassica genomes. Theor. Appl. Genet. 2016, 129, 1357-1372. [CrossRef]

51. Xing, G.M.; Long, M.H.; Tanaka, S.; Fujieda, K. Clubroot resistance in Brassicoraphanus [hybrid of cabbage $\times$ radish]. J. Fac. Agric. Kyushu Univ. 1989, 33, 189-194. [CrossRef]

52. Hagimori, M.; Nagaoka, M.; Kato, N.; Yoshikawa, H. Production and characterization of somatic hybrids between the Japanese radish and cauliflower. Theor. Appl. Genet. 1992, 84, 819-824. [CrossRef] [PubMed]

53. Akaba, M.; Kaneko, Y.; Hatakeyama, K.; Ishida, M.; Bang, S.W.; Matsuzawa, Y. Identification and evaluation of clubroot resistance of radish chromosome using a Brassica napus-Raphanus sativus monosomic addition line. Breed. Sci. 2009, 59, 203-206. [CrossRef]

54. Dodds, P.N.; Rathjen, J.P. Plant immunity: Towards an integrated view of plant-pathogen interactions. Nat. Rev. Genet. 2010, 11, 539-548. [CrossRef]

55. Mun, J.H.; Yu, H.J.; Park, S.; Park, B.S. Genome-wide identification of NBS-encoding resistance genes in Brassica rapa. Mol. Genet. Genom. 2009, 282, 617-631. [CrossRef]

56. Yu, J.; Tehrim, S.; Zhang, F.; Tong, C.; Huang, J.; Cheng, X.; Dong, C.; Zhou, Y.; Qin, R.; Hua, W.; et al. Genome-wide comparative analysis of NBS-encoding genes between Brassica species and Arabidopsis thaliana. BMC Genom. 2014, 15, 3. [CrossRef]

57. Wang, J.; Hu, T.; Wang, W.; Hu, H.; Wei, Q.; Bao, C. Investigation of evolutionary and expressional relationships in the function of the leucine-rich repeat receptor-like protein kinase gene family (LRR-RLK) in the radish (Raphanus sativus L.). Sci. Rep. 2019, 9, 6937. [CrossRef]

58. Wang, Y.; Song, Z.; Zhang, W.; Xu, L.; Su, X.; Muleke, E.M.M.; Liu, L. Identification and characterization of expressed TIR-and non-TIR-NBS-LRR resistance gene analogous sequences from radish (Raphanus sativus L.) de novo transcriptome. Sci. Hortic. 2017, 216, 284-292. [CrossRef]

59. Hulbert, S.H.; Webb, C.A.; Smith, S.M.; Sun, Q. Resistance gene complexes: Evolution and utilization. Annu. Rev. Phytopathol. 2001, 39, 285-312. [CrossRef] 